This is the author's final, peer-reviewed manuscript as accepted for publication. The publisher-formatted version may be available through the publisher's web site or your institution's library.

\title{
Children's self-efficacy and proxy efficacy for after-school physical activity
}

David A. Dzewaltowski, Karly S. Geller, Richard R. Rosenkranz, Konstantinos Karteroliotis

\section{How to cite this manuscript}

If you make reference to this version of the manuscript, use the following information:

Dzewaltowski , D.A., Geller, K.S., Rosenkranz, R.R., \& Karteroliotis, K. (2010).

Children's self-efficacy and proxy efficacy for after-school physical activity. Retrieved from http://krex.ksu.edu

\section{Published Version Information}

Citation: Dzewaltowski , D.A., Geller, K.S., Rosenkranz, R.R., \& Karteroliotis, K. (2010). Children's self-efficacy and proxy efficacy for after-school physical activity. Psychology of Sport and Exercise, 11(2), 100-106.

Copyright: Copyright @ 2009 Elsevier Ltd All rights reserved

Digital Object Identifier (DOI): doi:10.1016/j.psychsport.2009.08.001

Publisher's Link: http://www.sciencedirect.com/science/article/pii/S1469029209000946

This item was retrieved from the K-State Research Exchange (K-REx), the institutional repository of Kansas State University. K-REx is available at http://krex.ksu.edu 
David. A. Dzewaltowski, ${ }^{1,}$ Karly S. Geller ${ }^{2}$, Richard R. Rosenkranz ${ }^{2}$, Konstantinos

\section{Karteroliotis $^{3}$}

Children's self-efficacy and proxy efficacy for out-of-school physical activity

${ }^{1}$ Department of Kinesiology and Community Health Institute, Kansas State University, Manhattan, Kansas

${ }^{2}$ Department of Human Nutrition and Community Health Institute, Kansas State University, Manhattan, Kansas

${ }^{3}$ Department of Physical Education and Sport Science' University of Athens, 41 Ethnikis Antistassis, 17237, Dafne, Athens, Greece

Suggested citation: Dzewaltowski, D.A., Geller, K.S., Rosenkranz, R.R., \& Karteroliotis, K. (2010). Children's Self-Efficacy and Proxy Efficacy for Out-of-School Physical Activity. Psychology of Sport and Exercise, 11(2):100-106.

Running Head: Physical Activity Proxy Efficacy

Key Words: Youth, After-school, Exercise,

Abstract Word Count: 200 Words

Manuscript Word Count (less abstract and title): 4562

Data of Manuscript Submission:

\section{Address all correspondence to:}

David A. Dzewaltowski, Ph.D.

Professor and Head

Department of Kinesiology and

Community Health Institute

Natatorium 8

Kansas State University

Manhattan, Kansas 66506

Phone: 785-532-7750

Fax: $\quad 785-532-7733$

E-mail dadx@ksu.edu 


\begin{abstract}
Background: This study evaluated the validity of a scale to measure children's self-efficacy and proxy efficacy to influence others to provide physical activity opportunities for physical activity during out-of-school time.
\end{abstract}

Methods: Children attending after-school programs were measured on their height and weight and completed a survey. Analyses included exploratory factor analysis $(n=183)$, confirmatory factor analysis on a separate sample of children $(\mathrm{N}=107)$, and mixed-model analysis of covariance with school as a random effect and children group variables as fixed effects.

Results: A three-factor scale assessed children's confidence to be physically active (SEPA), confidence to influence their parents (PEPA-Parents), and confidence to influence after-school staff to provide physical activity environments (PEPA-Staff). Males had greater SEPA than females. Children who perceived greater PA opportunities during after school time had greater SEPA, PEPA-Parents, and PEPA-Staff than children attending schools with fewer after school opportunities. Children attending schools with lesser diversity and lower concentrations of lower-income students had greater PEPA-parents compared to children attending schools with greater diversity and higher concentration of lower-income students.

Conclusions: Physical activity self-efficacy and proxy efficacy scales demonstrated acceptable factorial validity, reliability, and criterion validity and differed based on characteristics of children and the environments in which they reside. 
An expert panel review of the scientific literature concluded that all school-age children and youth should participate in daily moderate and vigorous intensity physical activity for 60 minutes. ${ }^{1}$ Unfortunately, a number of children and youth are not meeting physical activity guidelines. ${ }^{2-3}$ To increase the prevalence of children meeting physical activity guidelines, there is a need for intervention strategies that are effective both during the school day and out-of-school. Of the 60 minutes each day, a reasonable standard for schools is to offer 30 minutes of activity during the day, which would require children to accumulate 30 minutes out side of the school. ${ }^{4-5}$ There is accumulating evidence for strategies to increase physical activity during the school day. ${ }^{4}$ However, due to increasing demands on schools to provide basic education, the after-school time represents the greatest opportunity to increase physical activity in children. ${ }^{6}$

Progress in developing effective strategies to promote physical activity after school may be accelerated by targeting the causal processes of behavior change that may be unique to out-ofschool settings. These causal processes or mediators of behavior change are variables that fall between the intervention strategy and physical activity. ${ }^{7-9}$ One theoretical framework that organizes mediators into testable hypotheses is social cognitive theory. Social cognitive theory proposes that these mediators operate within a complex interactive system of personal, environmental, and behavior variables. According to social cognitive theory, individuals can take control of this causal system by exerting human agency. The theory distinguishes between two forms of human agency, or the ability to exercise control over one's health behavior and quality of life: direct personal agency and proxy agency. ${ }^{10}$

Direct personal agency in children and youth has been examined by assessing selfefficacy, which is defined as children's confidence in their skills and abilities to be physically active to reach a desired outcome. ${ }^{11-16}$ The specific self-efficacy beliefs include confidence about 
the task (60 minutes of physical activity 5 days each week), confidence about self-regulation in the face of barriers ("I can be physically active during my free time on most days even if it is hot or cold outside"), and confidence in asking others such as parents and school staff for help to be physically active.

Although self-efficacy expectations about the physical activity task or about selfregulation in the face of barriers both draw on processes of behavioral change that require direct personal agency, confidence in getting help from others requires proxy agency. Proxy agency is reflected in self-efficacy judgments, but it can also be assessed directly by measuring children's proxy efficacy. We define proxy efficacy as an individual's belief in his or her skills and abilities to perform behaviors to influence others to provide the environmental conditions necessary to exert self-efficacy. It may be that beliefs about personal agency (self-efficacy) are distinct from beliefs about proxy agency (proxy efficacy). This may be especially true for children who may be confident that they can be physically active but lack the skills to influence parents and teachers to put them in environments conducive to physical activity. Many children and adolescents do not have direct control of the social conditions and institutional practices that provide the context for their physical activity choices.

There is some evidence that self-efficacy and proxy efficacy may be related, but independent mediators of physical activity behavior change. Ryan and Dzewaltowski ${ }^{15}$ conducted a preliminary study to compare the relationships between different types of selfefficacy and after school physical activity. Children in sixth grade reported their confidence to be physically active (physical activity self-efficacy), confidence to overcome barriers (barrier selfefficacy), confidence to ask parents, friends, and teachers to be physically active with them (asking efficacy), and environmental change self-efficacy. Although distinct from physical 
activity self-efficacy, the environmental change self-efficacy construct was measured by a scale that included both direct and proxy agency questions. Sixth graders indicated their confidence to find people to be active with them, to find places to be active, to find transportation to physical activities, and to ask/influence parents and teachers to create options for physical activity. Physical activity self-efficacy and environmental-change self-efficacy were independent predictors of physical activity.

A subsequent study developed measures that assessed self-efficacy and proxy efficacy for physical activity with middle school youth for school, after school, and home settings. ${ }^{13}$ This study showed that middle school youth's self-efficacy for physical activity was a separate but related construct to their proxy efficacy to influence their parents to help them be physical active and their proxy efficacy to influence school staff and after-school staff to provide supportive physical activity environments.

The primary purpose of the present study was to evaluate the validity and reliability of a multidimensional scale to assess both self-efficacy and proxy efficacy among individuals in late childhood after school. The focus here was on after-school time because home and after-school programs may be more amenable to change from a child's efforts, compared to the elementary school day, where the environmental conditions for physical activity are institutionalized and often under the control of written policy. We hypothesized that self-efficacy for physical activity, proxy efficacy to influence parents, and proxy efficacy to influence after-school staff would be independent but related constructs.

The secondary purpose of the present study was to investigate whether differences between groups of children that theoretically should differ (criterion validity) would be detected with the established measure. We examined demographic differences and group differences 
between children attending after-school programs with greater physical activity opportunities compared to children with fewer PA opportunities and between children attending schools with higher concentrations of school ethnic diversity and low socioeconomic status compared to lower school ethnic diversity and higher economic status. We hypothesized that self-efficacy and proxy efficacy would be greater in children attending schools with more PA opportunities and greater socioeconomic status compared to children attending schools with fewer PA opportunities and lower socioeconomic status.

\section{METHODS}

\section{Participants: Exploratory Factor Analysis}

Participants were fourth- (86\%), fifth- $(11.2 \%)$ and sixth-grade $(2.8 \%)$ students attending seven after-school programs on elementary school sites that were run as part of an after-school alliance of a Midwest United States town school district, Boys and Girls Club, County Cooperative Extension System, and other community partners. Children participating in the fourth-grade group $(\mathrm{n}=110)$ after-school program completed questionnaires regarding their physical activity and nutritional beliefs and behaviors. Of the 110 youth, 107 (97\%) had complete self and proxy efficacy physical activity scores. The mean age of the 107 students during the time of questionnaire completion was 10.3 years, ranging from 8.8 to 12.5 years. Fifty percent of the sample was female and $54 \%$ of the youths' households were of low income (i.e., receiving free and reduced meal program assistance). The sample was primarily white $(n=62)$, with some diversity (Black, $\mathrm{n}=30$; American Indian/Alaska native, $\mathrm{n}=1$; Hispanic/Latino, $\mathrm{n}=$ 5; Asian, $\mathrm{n}=1$; Native Hawaiian/other, $\mathrm{n}=8$ ). Of the data analyzed, $86 \%$ was collected during spring 2006 and 14\% during spring 2007. 
Physical Activity Proxy Efficacy

\section{Participants: Confirmatory Factor Analysis and Criterion Validity}

Participants' scores used to confirm the measurement model established in the initial EFA were obtained from fourth- (89.6\%), fifth- $(8.7 \%)$ and sixth-grade (1.6\%) students attending different semesters of the same after-school programs used for the EFA. Children $(n=187)$ completed identical questionnaires to those used for the initial EFA. Of the 187 youth, 183 (98\%) had complete self and proxy efficacy physical activity scores, which were analyzed in the current study. The mean age of the 183 students during the time of questionnaire completion was 9.7 years. Forty-seven percent of the sample was female and $40 \%$ of the youths' households were of low income (i.e., receiving free and reduced meal program assistance). The sample was primarily white $(\mathrm{n}=131)$, with some diversity (Black, $\mathrm{n}=30$; American Indian/Alaska native, $\mathrm{n}=$ 13; Hispanic/Latino, $\mathrm{n}=6$; Asian, $\mathrm{n}=2$; Native Hawaiian/other, $\mathrm{n}=1$ ). Of the data analyzed, 53\% was collected during fall 2005 and 47\% during fall 2006.

\section{Self-efficacy and Proxy Efficacy Measures}

Self-Efficacy for Physical Activity (SEPA). The self-efficacy measure was designed to assess confidence in response to the behavioral task and confidence in self-regulating in the presence of barriers. The one self-efficacy behavioral task item assessed confidence "that you can do physical activity 60 minutes each day," which is consistent with current public health recommendations for children. Physical activity was defined as "any play, game, sport or exercise that gets you moving, breathing harder, and your heart beating faster. Physical activity can be done in sports, playing with friends, or walking to school. Some examples of physical activity are running, brisk walking, rollerblading, biking, skateboarding, dancing, swimming, soccer, basketball, football, and volleyball)." Four questions addressed being physically active in the face of barriers (e.g., no matter how busy you are, even it is hot or cold outside). These 
barrier items were drawn from Saunders and colleagues ${ }^{, 17}$ validated instrument. However, the questions were designed consistent with social cognitive theory recommendations such that each question began with "How sure are you that you can do physical activity..." Youth responded using a three-point scale, choosing from "Not sure at all," "Somewhat sure," and "Very sure."

Proxy Efficacy for Physical Activity - Parent (PEPA-P). Proxy efficacy for physical activity from the parent was defined as a youths' confidence in their skills and abilities to get their parents to provide physical activity opportunities. The specific actions to create supportive environments were defined as: to plan, to transport, to find a place, and to find different types of physical activities. An example question was, "How sure are you that you can get your parents to help you plan to do your favorite physical activities?" In addition to five items that were drawn from a previously validated instrument for middle school students, ${ }^{13}$ children reported their efficacy for getting their parents to "Play outside with you or do physical activity/sports with you." Children responded to each item using a three-point scale, choosing from "Not sure at all," "Somewhat sure," and "Very sure."

Proxy Efficacy for Physical Activity - Staff (PEPA-Staff). PEPA-S was defined as children's confidence in their skills and abilities to get the after-school program teachers or staff members to provide him or her with physical activity opportunities. Similar to PEPA-P, youth specific actions for supportive environments included planning, transportation, finding a place, and provision of a variety of physical activities. An example question was, "How sure are you that you can get the teachers or staff members of the after-school program to find a place where you can be physically active?". In addition to three items that were drawn from a previously validated questionnaire for middle school students, ${ }^{13}$ children rated their confidence in getting the after-school staff to "Help you find different types of physical activities you can do." Again, 
youth responded to each item using a three-point scale, choosing from "Not sure at all," "Somewhat sure," and "Very sure."

\section{After School Environment Measures}

Perceived School PA Opportunity. Two items assessed children's perceived opportunities for PA during the after school program. Children responded on a three-point scale choosing from "Yes," "Don't know," or "No" for the following items: "There are a lot of chances for kids to get involved in physical activity at the after-school program" and "We are satisfied with the physical activities or sports offered at the after-school program." Children whose average response was more positive than "Don't know" were categorized as perceiving PA opportunities after school and children who responded with "Don't know" or "No" were categorized as not perceiving PA opportunities.

School Diversity-School Socioeconomic Status. Seven schools were grouped into two categories based on the percentage of students who qualified for free and reduced lunch and percentage $\%$ of students who were white or of diverse race and ethnicity. The higher diversity, lower socioeconomic status schools $(n=4)$ ranged from $63 \%$ of the students qualifying for free and reduced school meals to $89 \%$. These schools were approximately $50 \%$ diverse with one school having slightly lower diversity (28\%). The lower diversity, higher SES schools $(n=3)$ ranged in free and reduced status from $32 \%$ to $4 \%$ and in diversity from $13 \%$ to $24 \%$.

Weight Status. Children wore lightweight indoor clothing and no shoes and were measured on height and weight. Research assistants used portable stadiometers (Invicta Plastics, Ltd, Leicester, UK) and high precision digital scales (Seca Corp, 770, Germany) to measure height to the nearest $1.0 \mathrm{~cm}$ and weight to the nearest $0.1 \mathrm{~kg}$. Scales were calibrated daily with certified weights. Body mass index (BMI) was calculated as body weight divided by height squared 
$\left(\mathrm{kg} / \mathrm{m}^{2}\right)$. BMI scores were converted to percentiles using the age- and sex-specific norms CDC growth charts. ${ }^{18}$ Children's who were equal to or greater than the 85 th or 95 th percentile were classified as "overweight" and "at-risk for overweight."

\section{Procedures}

In the fall, at the beginning of the school year, children with active parental consent were measured on height and weight in a private setting at the after school program. Research assistants led groups of children through a paper-and-pencil survey that assessed demographic and psychosocial variables hypothesized to influence physical activity and fruit and vegetable consumption. Children were asked to follow along as the observer read each question aloud, insuring their understanding. In addition to verbal descriptions of physical activity, definitions and instructions were displayed on large poster boards and presented to the group. Children were asked to give examples of different types of physical activity followed by a brief response and discussion lead by the observer. Classroom incentives (i.e., colorful pencils, small toys) were used to increase youths' continued focus and completion of survey; however, no penalty for nonparticipation was employed. The procedures were approved by the Institutional Review Board (IRB) at a Midwest university.

\section{Statistical Analysis}

Exploratory Factor Analysis (EFA) was performed using SPSS 13.0 with principal axis factor extraction method, followed by direct oblique (oblimin) rotation. This rotation method was used due to hypothesized correlations among the underlying factor structures of self and proxy efficacy. The number of components retained was estimated using the criteria: (a) Kaiser's ${ }^{19}$ retention of factors with unrotated eigenvalues exceeding 1 , (b) scree test, ${ }^{20}$ and (c) 
factor loadings exceeding $0.40 .^{21}$ Internal consistency reliability for each sub-scale was estimated using Cronbach's alpha coefficients.

Secondly, a CFA was performed with Mplus 4.2 (Muthen \& Muthen, 2007) using a Weighted Least-Square with Mean and Variance Correction (WLSMV) Estimator function due to categorical data. A one-factor, two-factor and uncorrelated three-factor model were analyzed and compared to the hypothesized correlated three-factor model. The difference in $\chi^{2}$ values for models estimated with WLSMV is not distributed as $\chi^{2} ;^{22}$ therefore, the $\chi^{2}$ Diff test was calculated by comparing the derivatives of the less restricted model (hypothesized model) with the derivatives of the more constrained models. Additional fit indices included: standardized root mean square residual (SRMR), root mean square error approximation (RMSEA), comparative fit index (CFI), and Tucker-Lewis index (TLI). Guided by suggestions provided by Hu and Bentler, ${ }^{23}$ acceptable model fit by the criteria: SRMR $(\leq .08)$, RMSEA $(\leq .06)$, CFI $(\geq .95)$, and $\mathrm{TLI} \geq .95)$

Finally, criterion validity was examined using least squares (adjusted means) comparisons. Specifically, a mixed-model analysis of covariance (SAS Version 9.1, PROC MIXED) was used, including school, gender, ethnicity, socioeconomic status (SES), perceived after school opportunity for PA, and weight status in the model. Aside from school representing a random effect, all other variables were fixed.

\section{Results}

\section{Exploratory Factor Analysis}

The exploratory principal axis factor analysis (PAF) conducted on the 15-item self and proxy efficacy for physical activity items extracted four factors with eigenvalues greater than 1 . The fourth factor had a borderline eigenvalue (1.08) and was debatable according to a scree plot 
and theoretical reasoning; thus three factors were chosen for extraction. The Keiser-Meyer-Olkin test of sampling adequacy resulted in a coefficient of 0.81 , exceeding the minimum 0.60 standard requirement. Thus, the three-factor solution met all statistical criteria and accounted for approximately $55.6 \%$ of the variability among the 15 -items. Following oblique (oblimin) rotation, all items had factor loadings exceeding 0.40 on only one of the three identified factors confirming the inclusion of all 15 items. Table 1 illustrates the percent variance accounted for by each factor, as well as the factor structure and pattern coefficients.

The first factor, labeled proxy efficacy for physical activity from the parent (PEPA parent) included six items capturing youths' confidence to influence their parent and/or guardian to create an environment supportive of physical activity ( $\alpha=0.781)$. Factor two, labeled selfefficacy for physical activity (SEPA) consisted of five items reflecting youths' personal confidence to be physically active at levels meeting public health guidelines and to be physically active in the face of barriers $(\alpha=0.753)$. The third factor was labeled proxy efficacy for physical activity from after-school (PEPA-Staff). This final factor consisted of four items identifying youths' confidence to influence after-school staff to create an environment supportive of physical activity ( $\alpha=0.801$ ). Overall, the 15-item questionnaire demonstrated high internal consistency $(\alpha=0.840)$.

\section{Confirmatory Factor Analysis (CFA)}

Figure 1 depicts the complete specification of the 3 -factor model outlined from the results of the EFA. Also included in Figure 1 are all standardized estimates to their specified latent variables and the correlation matrix of all estimates. The first indicator of each latent variable (P1, S1 and E1) was used as a marker indicator for their corresponding latent variable (PEPAParent, PEPA-Staff and SEPA, respectively). The measurement model contained no double 
loading indicators and all measurement error was presumed to be uncorrelated. Accordingly, the model was overidentified with $39 d f$.

Each of the overall goodness-of-fit indices suggested that the measurement model fit well, $\chi^{2(39)}=47.902, p=0.155, \operatorname{SRMR}(=.067)$, RMSEA $(=.035)$, CFI $(=0.986)$, and TLI $(=$ 0.991). All freely estimated unstandardized parameters were statistically significant ( $p s<.001)$. The Inspection of residual variances and modification indices indicated one ill fit within the solution. Specifically, the second indicator of the latent factor PEPA-Parent (P2, "get your parents to give you a ride home from the after-school program") had high residual variance (.907) and a relatively high modification index (7.850); therefore, indicating that $91 \%$ of the observed variance in the PEPA-Parent indicator (P2) is estimated to be unique or error variance. However, all other residual variances were relatively low, ranging from .174 to .638. Aside from item P2, all other factor loading estimates were strongly related to their supposed latent factors $\left(\mathrm{R}^{2} \mathrm{~s}=.362-.826\right)$, consistent with the position that these scales are reliable indicators of the constructs SEPA, PEPA-Parent and PEPA-Staff. Finally, results demonstrated that the three latent variables (SEPA, PEPA-Parent and PEPA-Staff) were moderately correlated (ranging from .345 to .558$)$, which is in accord with previous evidence and theory.

In addition to the hypothesized correlated three-factor model, additional models were compared using $\chi^{2}$ difference test calculated by analyzing the derivatives of each model. Table 3 illustrates the values for the $\chi^{2}$ difference tests as well as comparable fit indices for each analyzed model (RMSEA, SRMR, CFI and TLI). The first model used for comparison was a one-factor model with all 15-items loading on one factor. The second was a two- factor model with the first factor including all self-efficacy items (SEPA) and the second factor combining all proxy items (PEPA-Parent and PEPA-Staff). The third model had factor loadings identical to the 
hypothesized models; however, the relationship between each of the three factors was fixed to zero. As seen in Table 3, the one-factor model, two-factor and the uncorrelated factor model all fit the data poorly, demonstrating inadequate fit indices. The $\chi^{2}$ difference test was then used to compare the additional models to the three-factor model. Results revealed that restrictions of the three comparison models significantly degraded the fit of the hypothesized model (all ps $<.001$ ).

\section{Criterion-Related Validity}

Table 2 reports the ability of the measure to distinguish between groups that should differ on the construct. Depicted are least square means for children's self-efficacy for physical activity, as well as proxy efficacy for both parents and after-school staff scales. Group differences were analyzed for gender, ethnicity, socioeconomic status as measured by household free and reduced lunch status, perceived physical activity opportunities in the after-school environment, and after-school environmental differences defined as school sites differing on concentration of low SES and diversity. Males were greater in self-efficacy for physical activity than females, $\mathrm{F}(1,171)=4.54, \mathrm{p}=.03$. Children who perceived that their after-school programs had greater opportunities for physical activity were more confident that they could get their parents to help them be physically active $(\mathrm{F}(1,176)=10.94, \mathrm{p}<.001)$ and they were more confident that they could get after-school staff to help them be physically active, $\mathrm{F}(1,176)=$ $15.99, \mathrm{p}=.001$. Finally, children attending schools with less concentration of low SES students and less diversity were more confident that they could influence their parents than children attending schools with greater concentrations of low SES students and greater diversity, F (1, 176) $=5.71, \mathrm{p}=.02$. 


\section{Discussion}

This study supported the hypothesis that self-efficacy for physical activity (PA), proxy efficacy to influence parents, and proxy efficacy to influence after-school staff to help provide supportive PA environments are independent but related constructs for children in late childhood. This study also supported the hypothesis that self-efficacy and proxy efficacy would differ based on characteristics of children and the environments in which they reside. Differences were found based on gender, perceptions of the after-school environment, and characteristics of school sites. Several conclusions can be made from these findings.

First, the item assessing self-efficacy for the physical activity task and the items assessing self-efficacy for physical activity barriers loaded on the same factor and this factor was related to the two proxy efficacy factors. This finding suggests that self-efficacy can be assessed as a unidimensional construct that is related but independent of proxy efficacy. In this study, there was only one task self-efficacy item compared to four barrier items. It may be that if we had included more task items on the scale, then the findings may have been different. We may have found that task and self-efficacy items measured two related but independent constructs.

Second, self-efficacy for physical activity is an independent but related construct to proxy-efficacy to influence parents and proxy efficacy to influence school staff. Past research by Saunders and colleagues ${ }^{17}$ developed a 15 -item self-efficacy measure with fifth-grade children that had three factors: support seeking, barriers, and positive alternatives. The barrier factor included items that were used in the self-efficacy measure in this study to assess self-efficacy to be physically active in the face of barriers such as being busy, tired, hot or cold, or having homework. The positive alternative factor measured self-efficacy for physical activity when direct personal agency required regulating human behavior in the face of barriers that were 
mainly attractive choices, such as watching TV or doing something else. The support seeking factor contained two self-efficacy task items, "I think I can be physically active most days after school" and "I think I have the skills I need to be physically active" with several proxy efficacy items, such as "I think I can ask my parent or other adult to take me to a physical activity or sport practice." It is interesting that in our study the task self-efficacy item loaded with the barrier items but in the Saunders and colleagues study, ${ }^{17}$ the task self-efficacy items loaded on the support seeking factor. It may be that the two task items loaded on this factor because the support seeking scale in the Saunders study was the first factor explaining the largest variance in the model. If there were more than two task items in the Saunders study, ${ }^{17}$ then they may have found that the support seeking scale only included proxy agency items and self-efficacy was an independent scale.

Subsequent recent research on the Saunders and colleagues ${ }^{17}$ scale established a unidimensional seven-item version for high school girls. ${ }^{14,24}$ A number of studies have demonstrated that an unidimensional self-efficacy measure is a useful tool to contribute to the literature. ${ }^{11-12,14,16,24-26}$ Alternatively, the present study and a few other studies have shown selfefficacy and proxy efficacy are multidimensional constructs in the physical activity domain. For example, a recent study by Dzewaltowski and colleagues ${ }^{13}$ reported findings that illustrated that self-efficacy for physical activity, proxy efficacy for school teachers and staff, and proxy efficacy for parents were separate but related constructs in middle school youth. Therefore, if the goal is to globally establish that self-efficacy correlates with physical activity or mediates the effectiveness of an intervention, then a unidimensional measure with a few items may be an appropriate choice. However, if the goal is to understand the processes of behavioral change to drive the development of intervention strategies then an unidimensional measure may lack the 
sensitivity to detect which mediation process is important in physical activity interventions for children and adolescents: personal or proxy agency.

Consistent with past studies, there were group differences in self-efficacy based on gender such that males were more confident than females, ${ }^{27-28}$ but there were no sex differences in proxy efficacy. The self-efficacy gender difference suggests that after school and parent physical activity promotion programs may need to be structured to raise the confidence of girls.

Children who perceived greater PA opportunities during after-school time had greater confidence in being physically active, and were confident that they could influence their parents and school staff. Social cognitive theory would propose that environmental opportunities are antecedents of physical activity. This hypothesis was supported in this study. We are unsure why proxy efficacy to influence parents would differ by perceptions in the differences in quality of after-school program opportunities. It may be that children who have been successful in influencing their parents to place them in environments with physical activity opportunities are in after-school programs with more physically active options. The findings regarding physical activity options are limited because the physical activity environment was not objectively assessed. Future studies need to determine if differences in self and proxy efficacy exist between children attending after school programs observed to have attractive physically active options compared to programs with fewer options.

Children who attend schools with lesser diversity and lower concentrations of lowerincome students were more confident that they could influence their parents compared to children attending schools with greater diversity and higher concentration of lower income students. Note, this difference was found after controlling for differences in individual diversity and household socioeconomic status. It may be that the neighborhoods that parents live 
in are reflective of the parents' responsiveness to students' needs. Alternatively, it may be that children attending these schools are provided with education programs that build their skills and make them more confident in asking their parents to provide physical activity options.

In conclusion, the measure of self and proxy efficacy for physical activity demonstrated acceptable factorial validity, reliability, and criterion validity in late-childhood students. Further research is necessary to determine if proxy efficacy is a central variable of the causal process that determines physical activity behavior change. One way to examine this question would be to develop interventions to increase PA targeting proxy efficacy skills and to examine whether proxy efficacy mediates the intervention's effectiveness. Because proxy efficacy for parents is a separate construct from proxy efficacy for after-school staff, it may be that these interventions need to consider separate strategies for increasing proxy efficacy at home versus in the afterschool environment. 
Physical Activity Proxy Efficacy

\section{Acknowledgments}

This study was supported by National Research Initiative Grant no. 2005-35215-15418

from the USDA Cooperative State Research, Education, and Extension Service Human Nutrition and Obesity Program. 


\section{References}

1. Strong WB, Malina RM, Blimkie CJ, et al. Evidence based physical activity for school-age youth. J Pediatr. 2005;146:732-737.

2. Kimm SY, Glynn NW, Kriska AM, et al. Decline in physical activity in black girls and white girls during adolescence. $N$ Engl J Med. 2002;347:709-715.

3. Levin S, Lowry R, Brown DR, Dietz WH. Physical activity and body mass index among US adolescents: Youth risk behavior survey, 1999. Arch Pediatr Adolesc Med. 2003;157:816-820.

4. Pate RR, Davis MG, Robinson TN, et al. Promoting physical activity in children and youth: A leadership role for schools: A scientific statement from the american heart association council on nutrition, physical activity, and metabolism (physical activity committee) in collaboration with the councils on cardiovascular disease in the young and cardiovascular nursing. Circulation. 2006;114:1214-1224.

5. Koplan JP, Liverman CT, Kraak VI, Committee on Prevention of Obesity in Children and Youth. Preventing childhood obesity: Health in the balance: Executive summary. J Am Diet Assoc. 2005;105:131-138.

6. Dzewaltowski DA. Community out-of-school physical activity promotion. In: Smith AL, Biddle SJH, eds. Youth Physical Activity and Inactivity: Challenges and Solutions. Champaign, IL: Human Kinetics Publishers, Inc; In press. 
7. Baranowski T, Lin LS, Wetter DW, Resnicow K, Hearn MD. Theroy as mediating variables: Why aren't community interventions working as desired? Annals of Epidemiology. 1997;7:S89s95.

8. Baranowski T, Anderson C, Carmack C. Mediating variable framework in physical activity interventions. how are we doing? how might we do better? Am J Prev Med. 1998;15:266-297.

9. Bauman AE, Sallis JF, Dzewaltowski DA, Owen N. Toward a better understanding of the influences on physical activity: The role of determinants, correlates, causal variables, mediators, moderators, and confounders. Am J Prev Med. 2002;23:5-14.

10. Bandura A. Social cognitive theory: An agentic perspective. Annual Review of Psychology. $2001 ; 52: 1-26$.

11. Dishman RK, Motl RW, Saunders R, et al. Self-efficacy partially mediates the effect of a school-based physical-activity intervention among adolescent girls. Prev Med. 2004;38:628-636.

12. Motl RW, Dishman RK, Ward DS, et al. Perceived physical environment and physical activity across one year among adolescent girls: Self-efficacy as a possible mediator? J Adolesc Health. 2005;37:403-408.

13. Dzewaltowski DA, Karteroliotis K, Welk G, Johnston JA, Nyaronga D, Estabrooks PA. Measurement of self-efficacy and proxy efficacy for middle school youth physical activity. $J$ Sport Exerc Psychol. 2007;29:310-332. 
14. Motl RW, Dishman RK, Trost SG, et al. Factorial validity and invariance of questionnaires measuring social-cognitive determinants of physical activity among adolescent girls. Prev Med. 2000;31:584-594.

15. Ryan GJ, Dzewaltowski DA. Comparing the relationships between different types of selfefficacy and physical activity in youth. Health Educ Behav. 2002;29:491-504.

16. Sherwood NE, Taylor WC, Treuth M, et al. Measurement characteristics of activity-related psychosocial measures in 8- to 10-year-old african-american girls in the girls health enrichment multisite study (GEMS). Prev Med. 2004;38 Suppl:S60-8.

17. Saunders RP, Pate RR, Felton G, et al. Development of questionnaires to measure psychosocial influences on children's physical activity. Prev Med. 1997;26:241-247.

18. Centers for Disease Control and Prevention. CDC growth charts 2000. Available at: http:www.cdc.gov/growthcharts. Accessed May 20, 2008.

19. Kaiser H. A note on guttman's lower bound for the number of common factors Multivariate Behavioral Research. 1961;1:249-276.

20. Cattell RB. The scree test for the number of factors. Multivariate Behavioral Research. $1966 ; 3: 245-276$

21. Gorsuch RL. Factor Analysis (2 ${ }^{N d}$ Ed.). ; 1983. 
22. Brown TA. Confirmatory Factor Analysis for Applied Research. New York London: The Guilford Press; 2006.

23. Hu L, Bentler PM. Cutoff criteria for for fit indexes in covariance structure analysis: Conventional criteria versus new alternatives. Structural Equation Modeling. 1999;6:1-55.

24. Dishman RK, Motl RW, Saunders RP, et al. Factorial invariance and latent mean structure of questionnaires measuring social-cognitive determinants of physical activity among black and white adolescent girls. Prev Med. 2002;34:100-108.

25. Motl RW, Dishman RK, Dowda M, Pate RR. Factorial validity and invariance of a selfreport measure of physical activity among adolescent girls. Res Q Exerc Sport. 2004;75:259-271.

26. Motl RW, Dishman RK, Ward DS, et al. Comparison of barriers self-efficacy and perceived behavioral control for explaining physical activity across 1 year among adolescent girls. Health Psychol. 2005;24:106-111.

27. Trost SG, Pate RR, Dowda M, Saunders R, Ward DS, Felton G. Gender differences in physical activity and determinants of physical activity in rural fifth grade children. $J$ Sch Health. 1996;66:145-150.

28. Wu SY, Pender N, Noureddine S. Gender differences in the psychosocial and cognitive correlates of physical activity among taiwanese adolescents: A structural equation modeling approach. Int J Behav Med. 2003;10:93-105. 
Table 1. Exploratory Factor Analysis Results for Self-Efficacy (SEPA), Proxy Efficacy for Parents (PEPA-Parent) and After School Staff (PEPA-Staff) Physical Activity Scales

\begin{tabular}{|c|c|c|c|c|}
\hline \multirow{2}{*}{$\begin{array}{l}\text { Factor Label } \\
\text { PEPA- Parent }\end{array}$} & \multirow{2}{*}{$\begin{array}{l}\text { Items } \\
\text { Get your parents to help you plan your favorite physical activities }\end{array}$} & \multicolumn{3}{|c|}{ Factor Loadings } \\
\hline & & .481 &.-.005 & -.128 \\
\hline & Get your parents give you a ride home from the after-school program & .583 & -.113 & .157 \\
\hline & Get your parents find a place where you can be physically active & .702 & .121 & -.094 \\
\hline & $\begin{array}{l}\text { Get your parents help you find different types of physical activities you can } \\
\text { do }\end{array}$ & .623 & .228 & -.027 \\
\hline & Get your parents play outside with you or do physical activity/sports with & .493 & .081 & -.153 \\
\hline & you & & & \\
\hline & Get your parents find time to be physically active with you & .477 & .049 & -.290 \\
\hline \multirow[t]{5}{*}{ SEPA } & You can do physical activity 60 minutes each day & .189 & .637 & .072 \\
\hline & You can be physically active no matter how busy your day is & -.073 & 638 & -.154 \\
\hline & You can be physically active no matter how tired you may feel & -.096 & .714 & .088 \\
\hline & You can be physically active even if it is hot or cold outside & .038 & .488 & .021 \\
\hline & You can be physically active even if you have a lot of home work & .047 & .611 & -.043 \\
\hline
\end{tabular}


Physical Activity Proxy Efficacy

\begin{tabular}{|c|c|c|c|c|}
\hline \multirow[t]{4}{*}{ PEPA-Staff } & Get the after-school staff to help you plan your favorite physical activities & .021 & -.087 & -.849 \\
\hline & Get the after-school help you find a ride home from the after-school program & .022 & -.082 & -.641 \\
\hline & Get the after-school help you find a place where you can be physically active & .010 & .290 & -.515 \\
\hline & $\begin{array}{l}\text { Get the after-school help you find different types of physical activities you } \\
\text { can do }\end{array}$ & .165 & .126 & -.688 \\
\hline Eigenvalues & & 4.82 & 1.94 & 1.59 \\
\hline$\%$ Percentage & & 32.1 & 12.9 & 10.6 \\
\hline Cumulative \% & & 32.1 & 45.0 & 55.6 \\
\hline
\end{tabular}


Table 2: Least Square Means and Standard Errors

\section{Group}

\section{Self-Efficacy}

Physical Activity

Parent

\section{Proxy Efficacy}

Staff

$\underline{\text { Gender }}$
Male ( $\mathrm{n}=97)$
$2.48 \pm .07^{*}$
$2.37 \pm .07$
$2.32 \pm .08$
Female $(\mathrm{n}=89)$
$2.33 \pm .07$
$2.30 \pm .07$
$2.30 \pm .07$

Ethnicity

Diverse $(\mathrm{n}=53)$

$2.42 \pm .09$

$2.31 \pm .08$

$2.34 \pm .09$

White $(\mathrm{n}=132)$

$2.39 \pm .07$

$2.36 \pm .06$

$2.29 \pm .07$

$\underline{\text { Household S.E.S. }}$

Not Eligible $(\mathrm{n}=109)$

$2.44 \pm .08$

$2.33 \pm .07$

$2.26 \pm .08$

Eligible $(\mathrm{n}=73)$

$2.37 \pm .07$

$2.34 \pm .07$

$2.3 \pm .07$

$\underline{\text { Weight Status }}$

$$
\text { Normal }(n=141)
$$

$2.36 \pm .07$

$2.28 \pm .06$

$2.27 \pm .07$

At Risk/Overweight ( $\mathrm{n}=45)$

$2.45 \pm .09$

$2.39 \pm .09$

$2.36 \pm .10$

Perceived School PA Opportunity
Opportunity $(\mathrm{n}=132)$
$2.49 \pm .06^{*}$
$2.50 \pm .05^{*}$
$2.53 \pm .06^{*}$
No-Unsure Oppor. $(\mathrm{n}=34)$
$2.32 \pm .09$
$2.17 \pm .10$
$2.09 \pm .10$

$\underline{\text { School Diversity-S.E.S. }}$

High Div.-Low S.E.S.

$2.37 \pm .08$

$2.22 \pm .07 *$

$2.32 \pm .08$

Low Div.-High S.E.S.

$2.44 \pm .09$

$2.44 \pm .08$

$2.30 \pm .08$ 
Table 3: Model Fit and $\chi^{2}$ Difference Testing for One-Factor, Two-Factor, and Three-Factor Models

\begin{tabular}{|c|c|c|c|c|c|c|c|c|c|}
\hline & $\chi^{2}$ & $d f$ & $p$ value & $\begin{array}{c}\chi^{2} \text { for diff } \\
\text { testing }\end{array}$ & $d f_{\text {diff }}$ & RMSEA & SRMR & CFI & TLI \\
\hline Three-Factor & 47.902 & 39 & 0.155 & & & 0.035 & 0.067 & 0.986 & 0.991 \\
\hline Two-Factor & 114.364 & 32 & 0.000 & 35.683 & 2 & 0.119 & 0.112 & 0.871 & 0.895 \\
\hline One-factor & 165.474 & 31 & 0.000 & 70.671 & 3 & 0.154 & 0.138 & 0.789 & 0.823 \\
\hline $\begin{array}{l}\text { Uncorrelated } \\
\text { Three-Factor }\end{array}$ & 184.769 & 22 & 0.000 & 60.450 & 2 & 0.201 & 0.214 & 0.744 & 0.698 \\
\hline
\end{tabular}

Note: All $\chi^{2}$ values for difference testing are statistically significant $(p s<.001)$, indicating that the two-factor, one-factor and uncorrelated model constraints significantly degrade the fit of the correlated three-factor model 


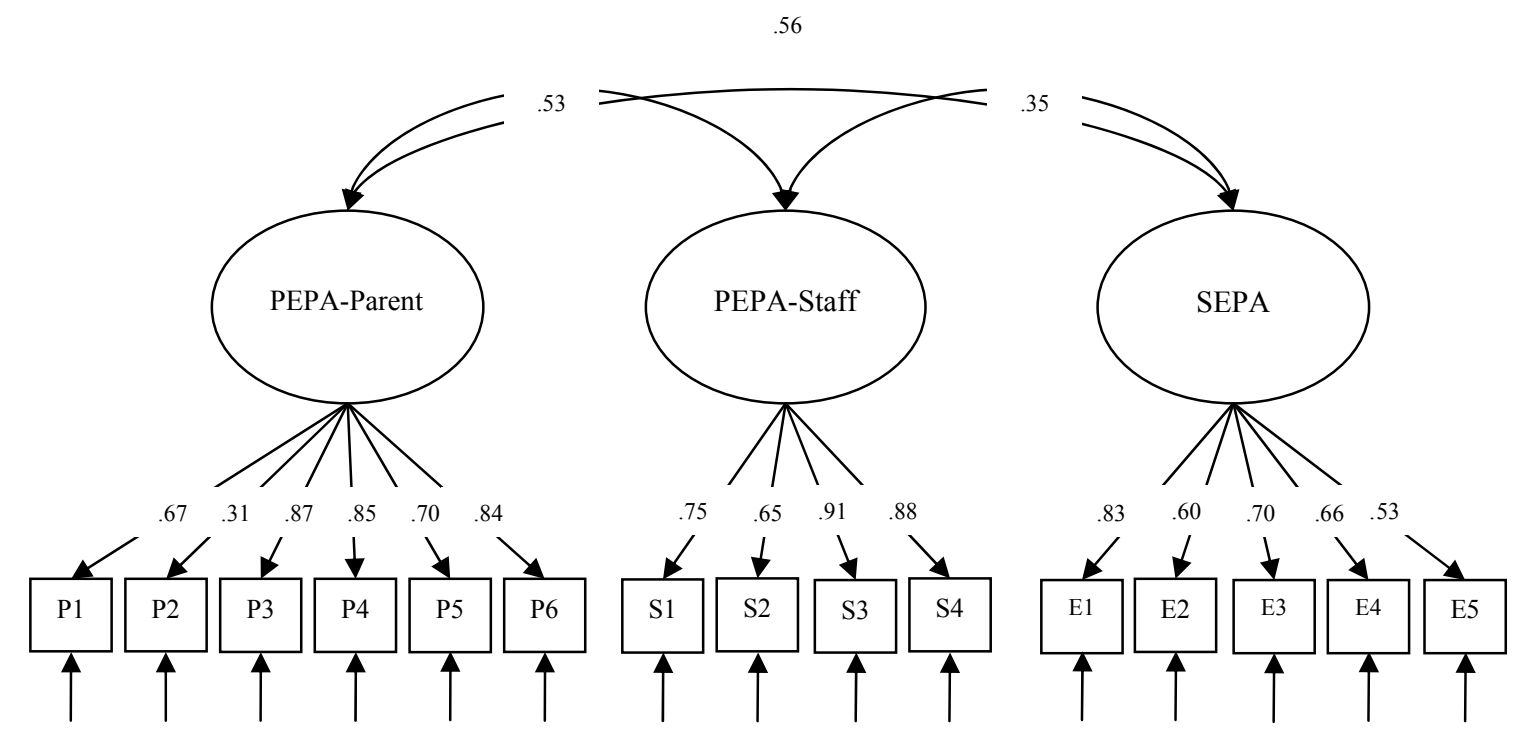

Figure 1. Path diagram with standardized estimates for three-factor CFA model of SelfEfficacy for PA (SEPA), Proxy Efficacy for PA from Parents (PEPA-Parent) and Proxy Efficacy for PA from after-school staff (PEPA-Staff) 